\section{Mit Humor in den Frühling}

- Vor ein paar Jahren konnte ich ein Interview mit dem Schriftsteller Martin Suter auf der Frankfurter Buchmesse verfolgen. Er wurde abschließend nach einem Lebensmotto gefragt. „Humor ist immer einen Versuch wert!“, war seine Antwort. Das fand ich sofort genial und erinnere mich seitdem oft daran. Den Gedanken trage ich wie einen Joker im Ärmel. Ich ziehe ihn, wenn sich Situationen „verkrampfen“. Können Sie sich das vorstellen? Kurz die Perspektive wechseln, kurze Analyse der Lage, überlegen, was eigentlich gerade passiert, und die - in der Regel vorhandene - Komik erkennen. Sehr befreiend! Nicht nur Stress, auch gute Laune steckt an!

_ Gegen Stress kennen wir viele Mittel. Gerade jetzt im Frühling steht sicher Bewegung - immerhin das zentrale „Heilmittel“ der Physiotherapie - an erster Stelle. Laufen, ausreichend Schlaf und Humor, vor allem Lachen, bauen Stress ab. Beschäftigen wir also so oft wie möglich unseren M. zygomaticus major. Er setzt am Jochbein an, zieht die Mundwinkel nach oben und übernimmt die Führung beim Lachen. Zahlreiche weitere Muskeln unterstützen ihn, unter anderem der M. risorius. Er verdankt seinen Namen dem Lachen (lat.: risus). Ohne den „Anführer“ und seine Mitarbeiter verginge ihm und uns das Lachen schnell. Teamarbeit ist gefragt. Und diese Teamarbeit erheitert uns dank Dopamin. Sobald wir den Witz einer Situation erkennen, wird Dopamin ausgeschüttet. Diesem Botenstoff verdanken wir Heiterkeit und gute Laune mit allen positiven Wirkungen auf unseren Organismus.

- Auch ein achtsamer Umgang mit eigenen Ressourcen beugt Stress vor und fördert Ausgeglichenheit. Der Artikel „MBSR: Stressbewältigung durch Achtsamkeit" führt in die Meditation der Achtsamkeit ein (๑ Seite 41). Schön, dass Achtsamkeit in Mode kommt. Achtsamkeit bedeutet, auf eine bestimmte Art aufmerksam zu sein: bewusst, im gegenwärtigen Augenblick und ohne zu bewerten. Das bezieht sich auch auf uns selbst. Ein achtsamer Umgang mit eigenen Ressourcen beugt Stress vor und fördert Ausgeglichenheit.

_ Ich möchte Ihnen beides für diesen Frühling ans Herz legen, Humor und Achtsamkeit.

Ihre
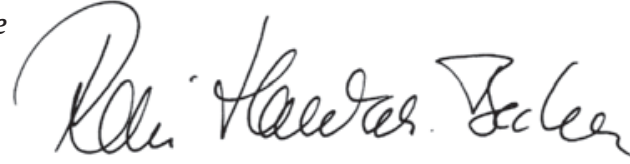

\section{PHYSIOBONUS}

physiobonus heißen die Gewinnspiele in physiopraxis. Wer teilnehmen möchte, nutzt das Formular unter www.thieme.de/ physioonline in der Rubrik physioexklusiv. Und das gibt es in dieser Ausgabe zu gewinnen:

Kursplatz

1 Kurs „Osteopathische viszerale Techniken im Bereich BWS/Rippen“

Seite 55

Bücher

2-mal „Dysphagie“

3-mal „Clinical Reasoning in der Manuellen Therapie“ Seite 35

3-mal „Meditation

für Neugierige

und Ungeduldige“

Seite 43

und außerdem

1 Einrad

Seite 40 